\title{
Changing the Lens: How Novel Videography Methods Can Improve Teacher Evaluation
}

\author{
James J. Brescia, E James L. Gentilucci \\ California Polytechnic State University
}

\begin{abstract}
School principals and university supervisors have limited time available for observing classroom teachers or teacher credential candidates as these individuals practice their craft in K-12 schools. Consequently, data capture during classroom observations is often perfunctory and fails to yield the type of information that can lead to substantial improvement in teaching practices. Traditional methods of videotaping the instructional performance of teachers and credential candidates are limited because they rely on "fixed-position" cameras focused solely on the teacher. Video data collected using these methods fails to capture information about how students respond to various instructional methods-critical information that can help practicing and aspiring teachers improve their pedagogical skills.

Consequently, an exploratory study was conducted to test the perceived usefulness of two novel videography methods-first-person and timelapse-for teacher and credential candidate evaluation purposes. Fifty administrators-intraining, 90 pre-service credential candidates, $20 \mathrm{~K}$ 12 classroom teachers, and $20 \mathrm{~K}$-12 students viewed video data captured in three formats-traditional, first-person, and time-lapse-and reported their perceptions of each method's usefulness for improving teacher practice. Results indicate that traditional and time-lapse videography methods capture useful data about teacher and credential candidate performance, but first-person videography provides the most beneficial data for improving instructional practice. Recommendations based on the findings are presented and discussed.
\end{abstract}

\section{Introduction}

Instructional supervision is arguably the most important responsibility of school principals and those who oversee the pedagogical development of aspiring teachers (e.g., university supervisors and cooperating master teachers). Formative evaluation is the cornerstone of this duty [3]. However, without a well-designed and properly implemented evaluation system, it is impossible to know if we have high quality instruction in our classrooms [18] or if credential candidates are mastering the skills necessary to become excellent teachers.

Unfortunately, the day-to-day demands of managing schools, teaching, and university responsibilities consume inordinate amounts of time and limit principals', cooperating teachers', and university supervisors' availability to conduct indepth formative teaching observations [1], [2], [9], [11]. Consequently, data capture during observations of classroom teachers and credential candidates is often conducted using a set of behavioral checklists (e.g., number and type of teacher questions, length of wait time, etc.). When this data capture method is combined with the all-too-frequent practice of "drive-by" classroom visits, evaluators fail to capture and provide teachers and credential candidates with detail-rich data about their (teachers' and candidates') instructional performance. Thus, teachers and candidates are often given marginally helpful evaluation commentary based on criterionreferenced rankings such as "exceeds expectations" or "needs improvement" on various domains of instructional practice. Such data-poor feedback may satisfy contractual or university obligations for evaluation but rarely helps teachers or candidates improve the quality of their instructional skills [19].

To address this problem, the authors revisited the practice of using traditional video recording (hereafter referred to as "videography") to collect data about teacher and candidate performance in the classroom. In addition to traditional videography, the authors used two innovative video methodsfirst-person and time-lapse- to capture unique data about instructional performance. The first-person videography technique was developed by Dr. Louis Rosenberg and a team of engineering students at California Polytechnic State University, San Luis Obispo (hereafter referred to as "Cal Poly"). It consists of mounting a tiny camera upon a ball cap that is worn by K-12 students during classroom 
lessons. The video recording depicts more than teacher performance-it also captures where students focus their attention during lessons. The video and audio data provide a “students' eye view" of instruction, thereby providing principals, cooperating teachers, and university supervisors with rich information about how K-12 students perceive the real-world instructional experiences.

The second innovation, use of time-lapse videography, results in high-speed recordings of teacher and candidate performance and makes it possible to view entire lessons in a matter of minutes. Although it does not capture fine nuances of instructional performance, it enables principals, cooperating teachers, and university supervisors to identify quickly how teachers and candidates use instructional time, how they move about the classroom, and how they interact with students.

These two innovations extend the power of traditional videography by addressing a number of its shortcomings. First, traditional videography captures "bounded" data about teachers and students because it relies on a camera positioned at a fixed vantage point in a classroom, usually at the back of the room. It focuses mainly on the teacher and only indirectly records students' responses to instruction. Consequently, it fails to capture the "naturalistic" environment of the classroom [7], [8], including information about where students are looking, when students are taking notes, what students are writing in their notes, when 12 students are watching the teacher, and when their attention is drifting [14].

Conversely, the first-person video method permits students situated in multiple locations to record data not only about the classroom teacher but also about their peers and the whole classroom environment, thereby transcending the artificial boundaries imposed by fixed location/observer videography. The cameras worn by students capture more authentic data about teacher or candidate practices as well as student responses to those practices. These data help teachers and candidates understand how engaged or disengaged students are during various instructional activities (e.g., lecture, demonstration, activity, or individual work).

Traditional videography also fails to provide information about students' perspectives of teacher or candidate performance. This is problematic because it is not possible to create and sustain effective learning environments without first understanding when students, the ostensible "consumers" of education, attend to various instructional processes [4], [8], [9], [19]. Like all people, K-12 students pay attention to what interests them and generally ignore that which does not. Continual measures (or observations) of where students focus (i.e., aim their camera) during lessons over multiple days reveal these patterns of student attention. When this process is repeated with multiple students in a teacher or candidate's classroom, a set of actions (i.e., responses to instruction) termed "perspectives" begins to emerge. For example, when a number of students attend to a particular instructional method such as a demonstration and consistently fail to attend to another such as lecture, it is possible to infer that the students under observation generally hold the perspective that lectures are not as valuable for learning as are demonstrations. Analysis of perspectives provides valuable information about adjusting instructional practice to improve student engagement and learning [3], [7], [8], [19].

Another major weakness of traditional videography is that it is often used as an "openended" data capture method. Observers generally start recording video at the outset of a lesson and stop when the lesson concludes. This method is inefficient because it captures everything that occurs within the boundary of the camera lens and records hours and hours of video that may include only short segments of actual teaching. Review of such video requires principals, cooperating teachers, and university supervisors to visually and mentally attend to long segments of mundane video footage as they attempt to capture information about minute-tominute events they observe, leaving open the possibility of attention lapses and failure to identify important patterns of teacher or candidate behavior [13].

Time-lapse videography provides a solution for this problem. This video method involves using a camera to capture a frame of video every $n$th second of elapsed time during a lesson. Thus, during a one hour lesson (i.e., 3,600 seconds), the video camera may only record every 10th second, compressing the lesson into six minutes of video. Time-lapse playback provides a condensed, "high speed" representation of classroom lessons and makes certain teacher behavioral patterns, especially ones that emerge slowly over long periods of time (e.g., teacher movement and interaction), more visually apparent and readily accessible for evaluation purposes [15].

In sum, the authors posited that current K-12 teacher and credential candidate observation and evaluation processes, constrained by time limitations and over-reliance on marginally informative data capture methods, could be substantially improved using fist-person and time-lapse videography. To that end, the authors designed a small scale exploratory study to test the accuracy of their supposition. 


\section{Design and Methodology}

Recall the central premise of this study: K-12 teacher and credential candidate observation and evaluation, arguably the most important duties of principals and university supervisors, are frequently done poorly with considerable negative consequences for teachers, candidates, and students. In response to this problem, the authors designed an exploratory study to compare the perceived strengths and weaknesses of traditional, first-person, and timelapse videography for capturing rich, authentic data for improving the evaluation process. Two research questions were developed to guide this investigation:

1. How do traditional, time-lapse, and first-person videography compare? That is, what unique information or perspectives are captured using each "lens"?

2. If, how, and to what extent do evaluators of K12 teachers (principals and mentor teachers) and credential candidates perceive first-person and time-lapse videography add value to data captured during observations when compared with traditional videography?

\section{Site Selection}

Once the research questions were formulated, purposeful convenience sampling was used to select a school for the study based in part on the willingness of the principal, teachers, and parents to grant access for data capture in the classrooms. Lincoln School ${ }^{1}$, a private K-8 co-ed institution, is located on the Central Coast of California in an area known for its agricultural production, tourism, and natural beauty. The school is located in a predominantly mixed suburban/rural community where viniculture, light manufacturing, retail, and tourism form the basis of the local economy.

Lincoln School's population reflects the demographics of its surrounding community and consists primarily of middle- and upper-middle class Caucasian students. The school also includes a small number of students from minority backgrounds and low- or moderate-income families (see Table 1 for demographic characteristics of study site).

Once negotiations for site access were concluded with the site principal and district administration, informed consent documents that explained the nature, purpose, and goals of the study as well as a request for voluntary participation were distributed to parents, teachers, staff, and students. No school faculty or staff selected to opt out of the study, and all completed consent forms provided by the principal. Only one parent requested that her child be excluded from any video footage collected during the study, and accommodations were made by the school to comply with this request. Once this process was complete, the authors met with school staff to determine the most effective and least disruptive method of collecting video data in each classroom.

Table 1. Study Site Characteristics

\begin{tabular}{lr}
\hline $\begin{array}{l}\text { Lincoln School Characteristics } \\
\text { Total Student Population }\end{array}$ & $\boldsymbol{N}$ \\
\hline Ethnicity of Students & $\mathbf{3 1 5}$ \\
$\quad$ Caucasian (\%) & 68 \\
African-American (\%) & 2 \\
Hispanic (\%) & 23 \\
Asian (\%) & 5 \\
Other (\%) & 2 \\
English Learners (\%) & 8 \\
Free/Reduced Price Meals (\%) & 22 \\
\hline
\end{tabular}

Even though all faculty and staff volunteered to participate in the study, not all teachers and students were selected for data collection. Again, purposeful sampling was used to select three grade levels of students-primary, elementary, and middle schoolbecause the authors wanted to test the effectiveness of the three data capture methods with students at different levels of social and academic maturation. Furthermore, the authors selected three teachers in these grade levels - a veteran teacher, a mid-career teacher, and neophyte teacher-so they could compare the usefulness of the data and findings for evaluating the instructional performance of each subgroup of teachers.

Finally, each grade level selected included English language learners and students with identified learning disabilities (see Table 2 for a description of additional characteristics of the study sample).

Table 2. Study Sample Characteristics

\begin{tabular}{lr}
\hline $\begin{array}{l}\text { Sample Characteristics } \\
\text { Number of Participants }\end{array}$ & $\mathbf{N}$ \\
\hline Grade Levels of Participants & $1^{\text {st }}, 5^{\text {th }}, 8^{\text {th }}$ \\
Gender of Participants & \\
$\quad$ Female (\%) & 52 \\
$\quad$ Male (\%) & 48 \\
Education Status of Participants & \\
$\quad$ English Language Learners (\%) & 5 \\
$\quad$ Attention Deficit Hyperactivity (ADH) (\%) & 8 \\
$\quad$ ADH Disorder (\%) & 7 \\
Resource Specialist Program (\%) & 5
\end{tabular}

Teachers and students at Lincoln School were briefed by the principal about the nature and purpose of the study, and all participants were given 
opportunities to ask questions. The principal then introduced the research assistants (i.e., engineering students) who would set up cameras and assist with technical matters during the video capture sessions. To ensure the "typicality" of the data capture (i.e., data not collected under artificial conditions), filming occurred on regular school days, during normal instructional hours, and at varied instructional times throughout each day. Class sessions during which guest speakers, exams, or other non-instructional activities occurred were excluded from data capture.

Because first-person videography required students to wear a ball cap with a camera, the authors and participating teachers agreed to permit a number of students to wear the caps at different times during different days prior to the start of data collection. This was done without recording data to mitigate possible behavioral effects associated with the introduction of these unique recording devices into the classroom [5]. As the novelty of wearing the ball caps tapered off, data capture began and continued on a weekly basis over the period of one academic term.

At the conclusion of the data collection phase of the study, the three types of video footage were transferred to DVD format to make the data analysis process more expedient. The data were reviewed by the authors and initial evaluations about the usefulness each videography format for teacher evaluation were recorded.

During the first year of the study, the authors presented the video data and an assessment rubric to a convenience sample of 50 administrators-intraining enrolled in the California Preliminary Administrative Services Credential program at Cal Poly and asked them to use the rubric to rate the usefulness of each video method for teacher evaluation purposes.

The administrators-in-training were asked to view video footage of the same classroom lessons displayed in the three different formats and then utilize the assessment rubric to rate the usefulness of each video format for evaluating the following seven characteristics of instructional performance: 1) style of lesson presentation, 2) clarity of lesson presentation, 3) questioning skills of the teacher, 4) types of responses to students' answers, 5) management of classroom climate, 6) student engagement and participation, and 7) teacher movement and interaction.

It is important to note that the authors explained to the administrators-in-training (and to subsequent sample groups) their (the authors') operationalized definitions of the selected characteristic of instructional performance. This was done to avoid any misinterpretation by the sample groups of what the authors meant by characteristics such as "style, clarity, interactions, etc.” The rubric was scored using a three-point scale where a rating of one equaled "least useful" and a rating of three equaled "most useful".

During the second year of the study, the same video footage and rubric were presented to a convenience sample of 90 credential candidates who were enrolled in an initial teacher certification program at Cal Poly. Additionally, a convenience sample of 20 practitioners from local school districts who were serving as cooperating or mentor teachers for Cal Poly (i.e., those who oversee student teaching experiences of credential candidates), was also asked to view and rate the value of the three video formats. Finally, 20 Lincoln School students, purposefully sampled from classes filmed during the study, were asked to view the video data and rate each videography method using the same rubric. The ratings by the $\mathrm{K}-12$ students were collected to provide triangulation data for the administrative and teacher groups.

Each group was given the exact same instructions for scoring the assessment rubric, and ratings were carefully evaluated by the authors to ensure a high degree of inter-rater reliability. Again, the authors sought to understand what, if any, differences in perceived usefulness of the video data emerged among these various groups.

\section{Findings}

The study participants each recorded 21 subjective ratings on the rubric - one for each of the three video formats across the seven different instructional characteristics. The data from the all participants were compiled and analyzed yielding a set of 21 mean values (M) (see Table 3).

\section{Table 3. All Participants' Perceived Usefulness of Videography Format $(N=180)$}

\begin{tabular}{|l|l|l|l|}
\hline \multicolumn{4}{|l|}{ Characteristics of Instructional Performance } \\
\hline Mean $(M)$ & Traditional & $\begin{array}{l}\text { Time- } \\
\text { Lapse }\end{array}$ & $\begin{array}{l}\text { First- } \\
\text { Person }\end{array}$ \\
\hline Style & 2.07 & 1.61 & $\mathbf{2 . 3 0}$ \\
\hline Clarity & 2.16 & 1.21 & $\mathbf{2 . 6 3}$ \\
\hline Questioning & $\mathbf{2 . 5 2}$ & 1.00 & 2.34 \\
\hline Responses & 2.38 & 1.09 & $\mathbf{2 . 5 8}$ \\
\hline Management & 1.75 & 1.72 & $\mathbf{2 . 6 9}$ \\
\hline Engagement & 1.75 & 1.65 & $\mathbf{2 . 7 7}$ \\
\hline Interactions & 1.67 & $\mathbf{2 . 6 8}$ & 1.64 \\
\hline Mean by Format & 2.04 & 1.57 & $\mathbf{2 . 4 2}$ \\
\hline
\end{tabular}

Note: Bold values displayed in shaded boxes denote respondents' choices of "most useful" videography format.

Looking first across the aggregated data for all four groups, the authors discovered that, on average, respondents rated the first-person format most useful 
for authentic data capture (combined mean scores [CMS] = 2.42). This format was followed next by traditional videography $(\mathrm{CMS}=2.04)$ and last by the time-lapse format (CMS = 1.57).

Further analysis of the aggregated data revealed the perceived usefulness of each video format varied by attribute of instructional performance used to assess instruction. When they compared the data from all groups on a characteristic-by-characteristic basis, the authors found the overall perceived usefulness of first person videography most helpful for assessing five of the seven instructional characteristics, especially student participation and engagement in lessons, but less so for assessing two characteristics (i.e., teacher questioning skills and teacher movement and interaction).

To test the trustworthiness of this finding, the authors disaggregated data by participant group to determine which format respondents perceived most effective for assessing each instructional characteristic. First-year data from the administrators-in-training are presented in Table 4, while second-year data from credential candidates, cooperating teachers, and students are presented in Tables 5 through 7 , respectively.

Table 4. Administrators' Perceived Usefulness of Videography Format $(N=50)$

\begin{tabular}{|l|l|l|l|}
\hline Characteristics of Instructional Performance \\
\hline Mean $(M)$ & Traditional & $\begin{array}{l}\text { Time- } \\
\text { Lapse }\end{array}$ & $\begin{array}{l}\text { First- } \\
\text { Person }\end{array}$ \\
\hline Style & 2.06 & 1.63 & $\mathbf{2 . 2 5}$ \\
\hline Clarity & 2.20 & 1.21 & $\mathbf{2 . 6 0}$ \\
\hline Questioning & $\mathbf{2 . 5 0}$ & 1.00 & 2.28 \\
\hline Responses & 2.44 & 1.13 & $\mathbf{2 . 5 6}$ \\
\hline Management & 1.82 & 1.78 & $\mathbf{2 . 7 1}$ \\
\hline Engagement & 1.81 & 1.71 & $\mathbf{2 . 8 2}$ \\
\hline Interactions & 1.61 & $\mathbf{2 . 8 3}$ & 1.61 \\
\hline
\end{tabular}

Table 5. Credential Candidates' Perceived Usefulness of Videography Format $(N=90)$

\begin{tabular}{|l|l|l|l|}
\hline \multicolumn{4}{|l|}{ Characteristics of Instructional Performance } \\
\hline Mean $(M)$ & Traditional & $\begin{array}{l}\text { Time- } \\
\text { Lapse }\end{array}$ & $\begin{array}{l}\text { First- } \\
\text { Person }\end{array}$ \\
\hline Style & 2.09 & 1.60 & $\mathbf{2 . 2 9}$ \\
\hline Clarity & 2.16 & 1.21 & $\mathbf{2 . 6 1}$ \\
\hline Questioning & $\mathbf{2 . 7 9}$ & 1.00 & 2.19 \\
\hline Responses & 2.29 & 1.14 & $\mathbf{2 . 5 4}$ \\
\hline Management & 1.76 & 1.65 & $\mathbf{2 . 5 7}$ \\
\hline Engagement & 1.76 & 1.59 & $\mathbf{2 . 6 5}$ \\
\hline Interactions & 1.78 & $\mathbf{2 . 5 3}$ & 1.65 \\
\hline
\end{tabular}

Table 6. Cooperating Teacher's Perceived Usefulness of Videography Format $(N=20)$

\begin{tabular}{|l|l|l|l|}
\hline Characteristics of Instructional Performance \\
\hline Mean $(M)$ & Traditional & $\begin{array}{l}\text { Time- } \\
\text { Lapse }\end{array}$ & $\begin{array}{l}\text { First- } \\
\text { Person }\end{array}$ \\
\hline Style & 2.11 & 1.58 & $\mathbf{2 . 3 1}$ \\
\hline Clarity & 2.18 & 1.22 & $\mathbf{2 . 6 2}$ \\
\hline Questioning & $\mathbf{2 . 6 0}$ & 1.00 & 2.31 \\
\hline Responses & 2.39 & 1.10 & $\mathbf{2 . 5 7}$ \\
\hline Management & 1.79 & 1.75 & $\mathbf{2 . 6 7}$ \\
\hline Engagement & 1.78 & 1.60 & $\mathbf{2 . 7 5}$ \\
\hline Interactions & 1.70 & $\mathbf{2 . 7 3}$ & 1.69 \\
\hline
\end{tabular}

Table 7. Students' Perceived Usefulness of Videography Format $(N=20)$

\begin{tabular}{|l|l|l|l|}
\hline Characteristics of Instructional Performance \\
\hline Mean $(M)$ & Traditional & $\begin{array}{l}\text { Time- } \\
\text { Lapse }\end{array}$ & $\begin{array}{l}\text { First- } \\
\text { Person }\end{array}$ \\
\hline Style & 2.00 & 1.63 & $\mathbf{2 . 3 5}$ \\
\hline Clarity & 2.10 & 1.21 & $\mathbf{2 . 7 0}$ \\
\hline Questioning & 2.20 & 1.00 & $\mathbf{2 . 5 8}$ \\
\hline Responses & 2.40 & 1.00 & $\mathbf{2 . 6 6}$ \\
\hline Management & 1.62 & 1.70 & $\mathbf{2 . 8 1}$ \\
\hline Engagement & 1.65 & 1.71 & $\mathbf{2 . 8 7}$ \\
\hline Interactions & 1.60 & $\mathbf{2 . 8 4}$ & 1.59 \\
\hline
\end{tabular}

All groups, with the exception of the K-12 students, reported similar ratings of the video formats, ranking first-person video most valuable for assessing style of lesson presentation, clarity of lesson presentation, types of responses to students' answers, management of classroom climate, and student engagement and participation. The students rated first-person rather than traditional videography most useful for assessing teacher questioning techniques, so the authors used a two-sample $t$-test to determine statistical significance of this difference in findings. They used the combined mean score on this characteristic from the first three groups (2.63) and the mean score from the student group (2.20) to calculate a $t$-observed value of 1.44 for the difference in means, and that value did not exceed the required $t$-critical value of 2.92 to prove the difference between mean scores was statistically significant at the $p=0.05$ level. Therefore, the authors concluded that the finding of rating agreement among all four groups was trustworthy and reportable.

Finally, the authors disaggregated the data by instructional characteristic to examine two interesting findings. First, participants in all four groups clearly rated time-lapse video most useful for assessing how teachers move about their classrooms and interacting with individual or groups of students. This finding suggests that the high-speed review (vis-à-vis time lapse videography) of classroom lessons is a powerful tool that can inform principals, 
credential candidates, and teachers about how they use movement for instruction and/or classroom management. Time-lapse also reveals interesting interaction patterns among teachers and students. From the video data, it was clear that some teachers repeatedly called on certain students during lessons or spoke more frequently to students seated in one section of the classroom. In a few instances, teachers demonstrated a clear pattern of calling on one gender repeatedly when they asked questions. Such findings provide important data points for teacher selfreflection and can be used to improve instructional effectiveness in the classroom, but they cannot be readily accessed by traditional videography.

Second, the head-mounted cameras worn by students during the lessons did indeed provide a "students-eye-view" of instruction. First-person video received the highest mean rating from all four groups for its usefulness for assessing student engagement and participation. While more intrusive than traditional videography (i.e., using headmounted cameras), this novel video method provides a unique view of student engagement not available from other forms of data capture. For example, commonly used data capture methods for determining levels of student engagement (e.g., classroom observation forms) rely on the perspectives of outside observers (usually school administrators) to determine levels of student engagement and reasons for student responses to various forms of instruction. Unlike first-person videography, however, these methods do not permit students themselves to provide direct information about what engages them during lessons. This is a key finding because students and teachers sometimes have different understandings of what constitutes an “engaging” lesson activity.

\section{Conclusion}

This study began by asking how traditional, time-lapse, and first-person videography methods compare, and how and to what extent evaluators of K-12 teachers and credential candidates perceive first-person and time-lapse videography add value to data captured during observations when compared with traditional videography. The findings from this study provide answers to both research questions and support the claim that, when combined with traditional videography, first-person and time-lapse video methods are valuable tools for capturing a complete and authentic picture of classroom teaching and learning.

The findings also inform our understanding of how to improve pre-service teaching evaluation, and could lead to changes in how supervisors and administrators use video data to coach credential candidates and teachers to greater levels of instructional performance. Therefore, the authors strongly suggest that these novel videography methods be broadly field tested in a variety of school settings to further assess their usefulness for enhancing teaching and learning in K-12 schools.

\section{References}

[1] Andrews, R. \& Soder, R. (1987). Principal leadership and student achievement. Educational Leadership, 44(6), 9-11.

[2] Archer, J. (2004, September). Putting out fires. Education Week, 24(3). Marion, OH: Editorial Projects in Education.

[3] Ball, D.L., Bass, H. (2000b). Making believe: The collective construction of public mathematics knowledge in elementary classrooms. In D. Philips (Ed.), Constructivism in education: Yearbook of the National Society for the Study of Education (pp. 193-224). Chicago: University of Chicago Press.

[4] Becker, H. S., Geer, B., \& Hughes, E. C. (1968). Making the grade: The academic side of college life. New York, NY: John Wiley \& Sons, Inc.

[5] Bogdan, R., \& Bilken, S. (1998). Qualitative research for education. An introductory to theory and methods. Boston: Allyn and Bacon.

[6] Cangelosi, J. S. 1984. Evaluating teaching: A suggestion for principals. NASSP Bulletin, 68, 19-23.

[7] Eckart, J. A., \& Gibson, S. L. (1993, May/June). Using camcorders to improve teaching. Clearing House, 66(5), 288-292.

[8] Gentilucci, J. L. (2004). Improving school learning: The student perspective. The Educational Forum, 68(2), 133-141.

[9] Gentilucci, J. L., \& Muto, C. C. (2007). Principals' influence on academic achievement: The student perspective. National Association of Secondary School Principals Bulletin, 91(3), 219-236.

[10] Gross Davis, B. (1993). Tools for Teaching. San Francisco: Jossey-Bass.

[11] Hallinger, P., Brickman, L. \& Davis, K. (1996). School context, principal leadership, and student reading achievement. The Elementary School Journal, 96(5), 527-549.

[12] Lieb, S. (1991, Fall). Principles of adult learning. Vision [on-line] Retrieved 11.5.05 http://honolulu.hawaii.edu/intranet/committees/FacDevCo m/guidebk/teachtip/adults-2.htm

[13] Livingstone, D. W. (2001). Adults' informal learning: Definitions, findings, gaps and future research. Toronto, ON. Centre for Educational Work. The Ontario Institute for Studies in Education. 
[14] Rosenberg, L., \& Gentilucci, J. L. (2007). The use of first-person videography to support teacher education. Paper published in the proceedings of the Association for the Advancement of Computing in Education 2007 Annual Conference, Vancouver, B.C.

[15] Rosenberg, L., \& Petersen, G. (2008, Spring). TimeLapse Video as a Self Reflection Tool for Collaborative Learning Projects. Journal of Research for Educational Leaders, Vol. 4, No. 2.

[16] Schifter, D. (1996, March). A constructivist perspective on teaching and learning mathematics. Phi Delta Kappan, 492-499.

[17] Thompson, T. S. (1992). Using videotape as a supplement to traditional student teacher supervision. Greenville, NC: East Carolina University. (ERIC Document Reproduction Service No. ED 357 014).

[18] Stronge, J. H., \& Tucker, P. D. (2003). Handbook on Teacher Evaluation: Assessing and Improving Performance. Larchmont, NY: Eye on Education.

[19] Struyk, L. R., \& McCoy, L. H. (1993, September/October). Preservice teachers' use of videotape for self-evaluation. Clearing House, 67(1), 31-35.

[20] Zepeda, S. J. (2003). Instructional supervision: Applying tools and concepts. NY: Eye on Education. 